\title{
LA CONSIDERACIÓN DEL TURISMO EN EL ORDENAMIENTO TERRITORIAL DEL MUNICIPIO DE SAN ANTONIO
} DE ARECO

Mg. Mauro Beltrami

Universidad Argentina de la Empresa.

Cuidad Autónonoma de Buenos Aires

Argentina.

0000-0002-1313-6105

\. mbeltrami@uade.edu.ar

\section{Mg. Maribel Carrasco}

Facultad de Humanidades y Ciencias de la Educación. Universidad Nacional de La Plata. La Plata, Argentina

iD) $0000-0003-0018-8237$

carrascomaribel@agro.uba.ar

\section{RESUMEN}

El trabajo analiza la forma en que la actividad turística es considerada en el Código de Ordenamiento Territorial del Municipio de San Antonio de Areco, un destino turístico consolidado que recibe afluencia turística nacional e internacional y que es un emblema del turismo rural en la pampa bonaerense, y en el que el turismo constituye uno de los rubros que más aportan al Producto Bruto Geográfico local. Del análisis del Código, se desprende que el uso turístico del suelo se aplica en forma limitada, dejando fuera a las áreas de mayor tránsito turístico. Se adopta un enfoque cualitativo-cuantitativo con la realización de entrevistas, una amplia investigación documental y recorrida de campo. Se prevé que este estudio resulte de utilidad para otros municipios de la Provincia de Buenos Aires en los que el turismo constituya una actividad económica de importancia.

\section{PALABRAS CLAVES}

uso turístico del suelo San Antonio de Areco destino turístico municipios ordenamiento territorial

LA CONSIDERACIÓN DEL TURISMO EN EL ORDENAMIENTO TERRITORIAL DEL MUNICIPIO DE SAN ANTONIO DE ARECO

\section{Autores:}

Mg. Mauro Beltrami y Mg. Maribel Carrasco
Recibido

23 de mayo, 2020

Aprobado

17 de julio, 2020

DOI

https://doi.org/10.24215/27186717e003
Ayana Revista de Investigación en Turismo

I Vol. 1 N 1 I Diciembre 2020 - Mayo 2021 ISSN 2718-6717

Entidad editora Instituto de Investigaciones en

Turismo, Facultad de Ciencias Económicas

(Universidad Nacional de La Plata)

La Plata I Buenos Aires I Argentina

http://revistas.unlp.edu.ar/ayana 


\section{THE CONSIDERATION OF TOURISM IN THE LAND USE} PLANNING OF THE SAN ANTONIO DE ARECO

\section{MUNICIPALITY}

\section{ABSTRACT}

The work analyses how tourism activity is considered in the Land Management Code of the Municipality of San Antonio de Areco, a consolidated tourist destination that receives a national and international tourism influx. It is an emblem of rural tourism in the Buenos Airean Pampa, in which tourism constitutes one of the areas that contribute the most to the local Gross Geographic Product. It is clear from the Code's analysis that the land is used by turists to a limited extent, leaving out the areas of greatest tourist traffic. A qualitative-quantitative approach is adopted with interviews, extensive documentary research and field tours. This study is expected to be useful for other municipalities in the Province of Buenos Aires where tourism is an important economic activity.

\section{KEYWORDS}

destination ${ }^{2}$ municipalities land use planning $>$ San Antonio de Areco $>$ tourist land use

\section{A CONSIDERAÇÃO DO TURISMO NO ORDENAMENTO TERRITORIAL DO MUNICÍPIO DE SAN ANTONIO DE ARECO}

\section{RESUMO}

O trabalho analisa como a atividade turística é considerada no Código de Ordenamento de Terras do Município de San Antonio de Areco, um destino turístico consolidado que recebe um fluxo nacional e internacional de turistas e é um emblema do turismo rural nas pampas de Buenos Aires, e no qual o turismo constitui um dos itens que mais contribuem para $\circ$ produto geográfico bruto local. A partir da análise do Código, parece que o uso turístico da terra é aplicado de maneira limitada, deixando de fora as áreas com maior tráfego turístico. Adota-se uma abordagem qualitativa-quantitativa, com entrevistas, extensa pesquisa documental e percorrida de campo. Espera-se que este estudo seja útil para outros municípios da província de Buenos Aires, onde o turismo é uma atividade econômica importante.

\section{PALAVRAS CHAVE}

destino turístico - municipios - San Antonio de Areco-uso do solo uso turístico do solo 


\section{Introducción}

Argentina no cuenta con una Ley Nacional de Ordenamiento Territorial (en adelante OT) y, por lo tanto, carece de un marco normativo específico que defina, organice y regule los usos del suelo a nivel nacional'. Existe una dispersión y/o atomización de la normativa ligada a la implementación de políticas de ordenamiento territorial. En particular, la provincia de Buenos Aires constituye una de las pocas provincias del país que cuenta con legislación en la materia. En esta, el OT se encuentra regulado por el Decreto Ley 8912/77, llamado "Ordenamiento Territorial y Uso del Suelo" (en adelante DL 8912/77). Se trata de una legislación de base que determina el marco jurídico para la regulación, ocupación, subdivisión y equipamiento del uso del suelo.

El DL 8912/77 establece que los municipios tienen la responsabilidad primaria del OT. Además, la norma fundamental que regula la organización de los municipios es el Decreto Ley 6769/58 llamado "Ley Orgánica de las Municipalidades" (en adelante LOM) con las modificaciones introducidas por numerosos Decretos-Leyes². De acuerdo con la competencia establecida por la LOM a los Concejos Deliberantes, los municipios bonaerenses tienen la facultad de regular y organizar el espacio de su jurisdicción, determinando los diferentes tipos de zonas e imponiendo restricciones y límites en los usos del suelo ${ }^{3}$. Si bien tanto el DL 8912/77 como la LOM habilitan a los municipios a la regulación del uso del suelo, debe considerarse que en la jerarquización del proceso de planeamiento, la primacía la continua sustentando la autoridad provincial ${ }^{4}$.

Los municipios históricamente han tenido debilidades institucionales que limitaron sus procesos de planificación. Recién en la década de 1990, los municipios comenzaron a asumir nuevas responsabilidades de gestión, pasando de ser administraciones básicas a gobiernos locales (Grandinetti y Nari 2016). En este contexto, la planificación territorial es adoptada como una herramienta de gestión municipal.

Los procesos de OT contemplan las actividades económicas que se desarrollan en una jurisdicción, incluyendo a la actividad turística en los municipios donde aporta significativamente a su Producto Bruto Geográfico (en adelante PBG). Como plantean Rossi et. al (2018) el turismo se despliega en el marco de la complejidad del territorio, interactuando con los distintos actores y en estrecha interrelación con las distintas dimensiones sociales, económicas y ambientales. Al territorio se lo entiende como un espacio "donde se manifiestan y dirimen los conflictos económicos, sociales, políticos y culturales, donde se lucha por las conquistas de los respectivos intereses y donde se disputa el po-

\footnotetext{
' Hay antecedentes de iniciativas para la regulación nacional del ordenamiento territorial. Por ejemplo, en el año 2004 se instituyó el Plan Estratégico Territorial (PET) bajo la coordinación del Estado Nacional, articulado con las Provincias y la Ciudad Autónoma de Buenos Aires. Asimismo, durante la presidencia de Cristina Fernández de Kirchner (2007-2015), se proyectó la creación de una Ley Nacional de Desarrollo y Ordenamiento Territorial, con miras a establecer una Ley Marco para la planificación del desarrollo territorial, procurando que, más allá de las legislaciones provinciales o locales preexistentes, sirviera de referencia para las leyes que consecuentemente pudieran dictarse en el futuro. Finalmente, la iniciativa no se tradujo en una Ley aprobada por el Congreso Nacional y la implementación del PET perdió la posibilidad de contar con un sustento legal que le diera continuidad, quedando supeditado a la voluntad de los decisores de cada nivel de gobierno.

${ }^{2}$ Los Decretos-leyes son: 7.443/68, 8.613/76, 8.752/77, 8.851/77, 9.094/78, 9.117/78, 9.289/79, 9.443/79, 9.448/79, 9.926/83,

$9.950 / 83$ y $10.100 / 83$ y las Leyes: $5.887,5.988,6.266,6.896,10.140,10.164,10.251,10.260,10.377,10.706,10.716,10.766$,

$10.857,10.936,11.024,11.092,11.134,11.239,11.240,11.300,11.582,11.664,11.690,11.741,11.757,11.838,11.866,12.076$,

$12.120,12.288,12.396,12929,13101,13154,13217,13580,13924,14062,14139,14180,14199,14248,14293,14344,14393$,

$14480,14491,14515$ y 14449

${ }^{3}$ Decreto Ley N 6.769/58, artículos 27 y 28 (este último, texto según Decreto Ley 9094/78)

${ }^{4}$ Esto sucede porque toda propuesta de ordenamiento territorial que formulen los municipios debe ser aprobada por el Gobierno de la Provincia, Art. $N^{\circ} 83$ de la LOM.
} 
der político y económico" (Manzanal 2007: 25). En otras palabras, el territorio es una construcción social y la práctica turística se despliega en un marco de interacciones sociales en los que el componente de conflictividad está presente.

El régimen municipal bonaerense no determina con precisión las funciones específicas que los municipios deberían asumir en relación a la actividad turística, con la excepción de "la conservación de monumentos, paisajes y valores locales de interés tradicional, turístico e histórico", que es una atribución de los Concejos Deliberantes (Art. 27 - Decreto Ley $\left.N^{0} 6.769 / 58\right)^{5}$. No obstante, queda manifiesta la ligazón entre las competencias de los municipios para el OT y la regulación de sitios o paisajes de interés turístico.

La planificación territorial es una herramienta aún incipiente en los municipios bonaerenses. Más aún, la incorporación de la actividad turística en el OT. Tomando en cuenta que San Antonio de Areco (en adelante, SAA) es uno de los pocos municipios de la provincia de Buenos Aires que cuenta con un plan de OT, el presente trabajo explora y analiza los mecanismos de inclusión de la dinámica turística en este.

\section{Metodología}

El presente trabajo consiste en un estudio de caso de carácter exploratorio, el cual tiene como fin analizar y evaluar diversos factores de una determinada situación. La estrategia metodológica del estudio de caso tiene la capacidad de suministrar información detallada y específica, espacial y temporal sobre un hecho o fenómeno contemporáneo claramente delimitado, a los fines de comprender sus fundamentos para llegar a la interpretación más cercana a la realidad. "Debemos tener en cuenta que, dentro de la complejidad de un estudio de caso como enfoque metodológico, la intención es dar respuesta a cómo y por qué ocurren el o los hechos, focalizando en los fenómenos en estudio desde múltiples perspectivas, haciendo que la exploración sea en forma más profunda y el conocimiento obtenido sea más amplio" (Chaves et al., 2016, p. 9).

Asimismo, distintos autores recomiendan que, para un estudio de caso, se debe utilizar una combinación de técnicas para obtener la información, realizar una triangulación entre las distintas fuentes de datos y usar diferentes herramientas tanto cuantitativas como cualitativas (Stake 2006, Yin 1994 y Creswell 1998). De esta manera, la presente investigación tuvo un enfoque mixto, comprendiendo los tipos de investigación cuantitativa y cualitativa. "Los métodos mixtos representan un conjunto de procesos sistemáticos, empíricos y críticos de investigación e implican la recolección y el análisis de datos cuantitativos y cualitativos, así como su integración y discusión conjunta, para realizar inferencias producto de toda la información recabada y lograr un mayor entendimiento del fenómeno bajo estudio" (Hernández, Sampieri y Mendoza, 2008).

Este método permite la utilización de información obtenida por medio de distintos instrumentos y fuentes tanto primarias como secundarias. En el presente estudio, se realizó un relevamiento de información de fuentes primarias y secundarias. En el primer caso, se efectuaron entrevistas semiestructuradas a informantes clave: funcionarios municipales, emprendedores, inversores, guías de turismo y otros y se realizaron numerosas recorridas de campo en las

${ }^{5}$ Artículo 27 del Decreto Ley $N^{\circ} 6.769 / 58$, 
tres localidades del distrito. En el segundo caso, se llevó adelante una amplia investigación documental que incluyó el análisis de documentos y datos estadísticos oficiales (municipales, provinciales y nacionales), ordenanzas municipales y sus anexos como el propio Código de Ordenamiento Territorial, y publicaciones científicas. También se utilizaron herramientas de Sistemas de Información Geográfica (SIG) para representar espacialmente el contenido del Código y las áreas de interés turístico para su posterior análisis.

\section{Antecedentes del Ordenamiento Territorial en los municipios bonaerenses y la actividad turística}

En relación al Ordenamiento Territorial, señala Alves Rolo (2013: 25) que, "el carácter polisémico y multidimensional del término ha permitido que el ordenamiento territorial fuese definido, sucesiva o simultáneamente, como: una política de estado, un instrumento de política pública, un proceso de planificación técnico-político, un proceso técnico-administrativo, un instrumento de planificación estratégica, una estrategia para la toma de decisiones sobre el territorio, una estrategia de desarrollo, una disciplina científica, entre otras. Tal dispersión conceptual se explica tanto por la relativa juventud del término como por la amplia difusión que ha adquirido en distintas disciplinas".

A pesar de la diversidad conceptual del término, en este artículo se considera al Ordenamiento Territorial como un instrumento de política pública que requiere abordajes interdisciplinarios y que debe sustentarse en instrumentos técnicos, jurídicos (leyes, decretos, ordenanzas y otros), prácticas administrativas y principios de acción (planificación estratégica) y procesos de participación social (Carrasco 2018: 9).

En la provincia de Buenos Aires la regulación del uso del suelo establecida por el Decreto Ley 8912/77 indica que el OT es un método de ordenamiento físico del territorio "estructurándolo en áreas, subáreas, zonas y distritos vinculados por la trama circulatoria y programando su desarrollo a través de propuestas de acciones de promoción, regulación, previsión e inversiones, mediante métodos operativos de ejecución en el corto, mediano y largo plazo, en el cual deberán encuadrarse obligatoriamente los programas de obras municipales, siendo indicativo para el sector privado"6. Asimismo el DL 8912/77 establece que los municipios son quiénes tienen la responsabilidad primaria del $\mathrm{OT}^{7}$. Las Municipalidades cuentan con poder de policía asociado al cumplimiento de sus competencias y facultades en todo su territorio ${ }^{8}$; donde los códigos de faltas municipales permiten sancionar las infracciones a los códigos de OT?

El DL 8912/77 indica que el proceso de planeamiento debe considerar las siguientes etapas sucesivas: 1. Delimitación preliminar de áreas. 2. Zonificación según usos. 3. Planes de ordenamiento municipal. 4. Planes particularizados. A pesar de esta potestad, como señala Ríos (2017: 14) hasta el año 2017 "el estado del proceso de planeamiento a nivel municipal, en el marco del Decreto Ley ${ }^{\circ}{ }^{\circ} 8912 / 77$, demuestra que el avance hacia procesos planificados es mínimo encontrándose la mayor parte en las instancias iniciales". En efecto, son muy pocos los municipios que han logrado cumplir las cuatro etapas del proceso de planeamiento que indica el DL 8912/77. La carencia de herramien-

${ }^{6}$ Decreto Ley $N^{\circ} 8912 / 12$, artículo 80.

7 Decreto Ley $\mathrm{N}^{\circ} 8912 / 12$, artículo 70.

${ }^{8}$ Decreto Ley 6.769/58, artículo 286 (Texto incorporado por Ley 11.092)

9 Decreto Ley $N^{\circ} 8912 / 77$, artículo 93 
tas de planificación territorial se repite en numerosos municipios bonaerenses (Ríos, 2017). El modelo administrativista burocrático ha sido el preponderante, con un limitado grado de modernización y profesionalización de los recursos humanos y escasa planificación (García Delgado, 1998). De hecho, los municipios han tenido una limitada capacidad técnica para implementar eficazmente herramientas de planificación territorial. Sin embargo, desde la década de 1990, siguiendo lo expuesto por Reese (1999), en las provincias y municipios "surgió el replanteo de la planificación como una instancia necesaria para la resolución, evaluación y prospección de diferentes complejidades dentro de la búsqueda de mayores niveles de eficiencia".

En el caso de San Antonio de Areco, el Municipio, en el marco del DL 8912/77 elaboró un COT en el que se establece el marco jurídico del OT y en relación a la actividad turística, es el que determina y prioriza las áreas de uso turístico y de esta manera orienta las inversiones para el desarrollo turístico, en un distrito que es uno de los principales destinos turísticos de la provincia de Buenos Aires. No hay unanimidad académica en la definición de lo que constituye un destino turístico. A los efectos del presente trabajo, desde una perspectiva económica, puede ser entendido como "un área delimitada de territorio cuyas estructuras y actividades turísticas muestran tal grado de homogeneidad que permite la ejecución de una política turística común y uniforme para toda el área, así como una percepción de totalidad por parte del consumidor de los servicios turísticos que suele generarse en base al posicionamiento de la marca - la imagen del destino en su mente" (Norma UNE 178501:2016: Pág. 17). La intervención de un municipio a nivel territorial y turístico es compleja y multidimensional. Desde la planificación municipal, el territorio no debe ser visto como un contenedor de turismo, sino como productor y dinamizador, favoreciendo un desarrollo equilibrado siguiendo los principios de los destinos turísticos inteligentes: la innovación, la aplicación de tecnologías, la sustentabilidad y la accesibilidad (Elverdín 2014: 46) ${ }^{10}$.

El turismo, al igual que cualquier otra actividad económica que se asienta en el territorio, repercute en éste y lo transforma. El desarrollo sostenible debería considerarse en las políticas de desarrollo turístico (OMT 2017, Apartado 6) ${ }^{11}$. De hecho, uno de los principios rectores de la Ley Nacional N ${ }^{0} 25.997$ (Ley Nacional de Turismo) es el desarrollo sustentable $^{12}$. Siguiendo lo anterior, la actividad turística se podría incluir en los planes de OT impulsando estrategias orientadas al cumplimiento de los objetivos de desarrollo sostenible. El DL No 8912/77 menciona entre los objetivos del OT a "la preservación de las áreas y sitios de interés natural, paisajístico, histórico o turístico, a los fines del uso racional y educativo de los mismos"13. Esta resulta la única referencia al turismo en la normativa provincial, siendo usado el adjetivo "turístico" como caracterización de algún área o sitio. Lo cual dificulta integrar la dinámica de dicha

\footnotetext{
10 El desarrollo innovativo consiste en "la generación de capacidades de resolución sistémica de problemas", permitiendo "anticiparse a los problemas diagnosticando certeramente los senderos de investigación y apuntando a la generación de dinámicas locales de producción, cambio tecnológico e innovación socio-técnicamente adecuadas" (Elverdin 2014: 46)

${ }^{11}$ En este sentido, la OMT expuso que "para avanzar y cumplir con la Agenda para el Desarrollo Sostenible en 2030 y más adelante, es necesario, entre otras cosas, establecer y adoptar enfoques de planificación turística destinados a mejorar la eficiencia de los recursos de las partes interesadas en el turismo. Por ejemplo, el enfoque de la economía circular, que promueve modelos comerciales basados en recursos renovables, productos con ciclos vitales más largos y diversos, el consumo compartido y las cadenas de valor interconectadas, puede desempeñar un papel significativo en el diseño y la mejora de los sistemas de gestión de recursos, no solo en el sector turístico, sino también en el desarrollo sostenible de los destinos". ${ }^{12}$ Allí se establece que "el turismo se desarrolla en armonía con los recursos naturales y culturales a fin de garantizar sus beneficios a las futuras generaciones. El desarrollo sustentable se aplica en tres ejes básicos: ambiente, sociedad y economía". Ley Nacional № 25.997, artículo 2.

${ }^{13}$ Decreto Ley $N^{\circ} 8912 / 77$, artículo 2.
} 
actividad en los procesos de ordenamiento, particularmente en localidades como SAA que constituyen además destinos turísticos consolidados.

\section{Caracterización de San Antonio de Areco}

El Partido de SAA se ubica en la región norte de la Provincia de Buenos Aires, en las proximidades de la RMBA (Mapa $\mathrm{N}^{\circ} 1$ ). Es un municipio del interior de la provincia, aunque mantiene una estrecha relación con la RMBA. SAA limita al Norte con los partidos de Capitán Sarmiento y Baradero, al Este con el partido de Zarate, al Sudeste con los partidos de Exaltación de la Cruz y San Andrés de Giles, y al Oeste con Carmen de Areco. El distrito tiene tres localidades, Duggan, Villa Lía y la localidad homónima ${ }^{14}$-ver Mapa №2-.

Mapa N $N^{\circ}$ : Las Coronas de la RMBA y la localización del Partido de San Antonio de Areco

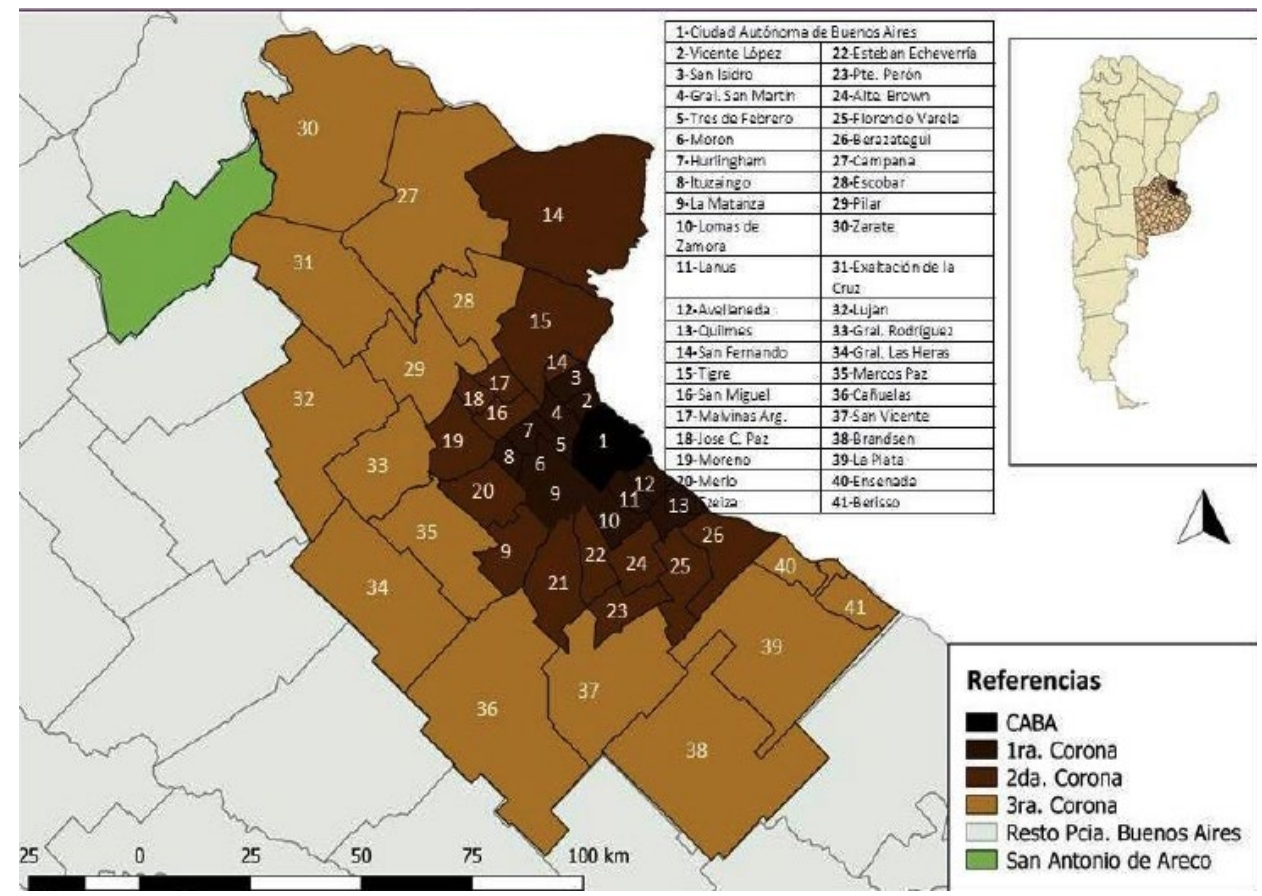

Fuente: Elaboración propia en base a la cartografía del IGN y URBASIG

El municipio tiene una superficie de $857 \mathrm{~km}^{2}$, ubicada dentro del área geográfica denominada "Pampa Ondulada", presenta un clima templado y húmedo con veranos calurosos e inviernos suaves. Su territorio se asienta en suelos característicos de la llanura pampeana que corresponden al grupo de los argiudoles típicos cuyo material original predominante es el loess, caracterizados como fértiles y profundos (Flores et al. 2013). Son suelos con óptimas

\footnotetext{
${ }^{14}$ Se excluye aquí a Vagues, un paraje lindero a la Estación Ferroviaria Vagues, que durante los Censos Nacionales de Población y Vivienda del INDEC de 2001 y 2010 fue considerada como población rural dispersa. Actualmente, Vagues constituye un área periurbana de la ciudad de San Antonio de Areco, no contando tampoco con Delegado Municipal propio.
} 
condiciones para la explotación agropecuaria, manteniendo ventajas comparativas en relación con otros partidos (Plan de Ordenamiento Territorial del Partido de San Antonio de Areco-2007).

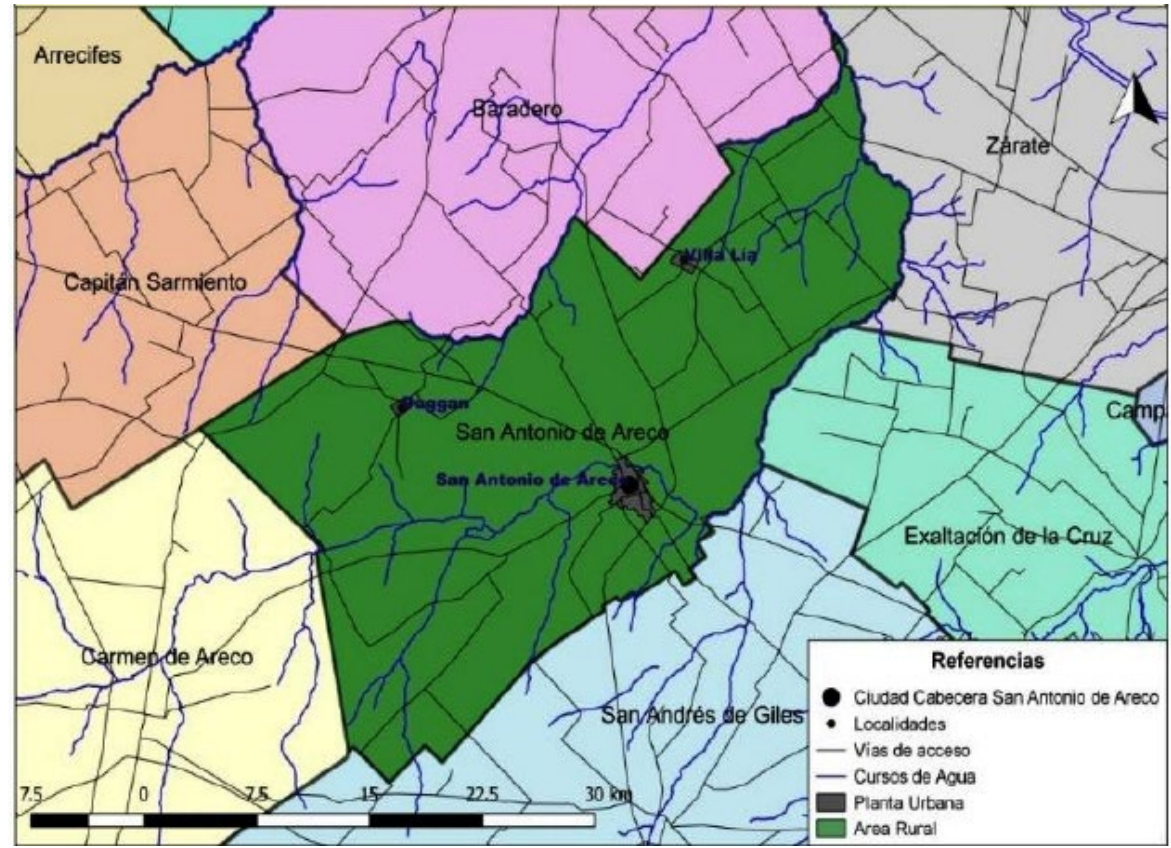

Fuente: Elaboración propia en base a cartografía del Instituto Geográfico Nacional y URBASIG.

La RN N 8 y RN N 9 comunican al Municipio con la CABA. SAA es un municipio en transición entre el área metropolitana y el interior provincial. Esta doble condición geográfica le genera tanto oportunidades como amenazas. Su cercanía con la RMBA le brinda a SAA mayores oportunidades económicas, aunque la mejora de los accesos a la metrópoli contribuye a la llegada de problemáticas sociales más propias de las grandes aglomeraciones urbanas.

La agricultura y la ganadería constituyen las principales actividades económicas de SAA. La industria se encuentra principalmente relacionada con el sector agropecuario y con la elaboración de productos alimenticios. Por último, la actividad turística tiene una importancia significativa en el PBG municipal.

Siguiendo lo expuesto, los usos y las ocupaciones del suelo se asocian no solamente a los residentes de las localidades del distrito, sino también a personas que utilizan a SAA como lugar turístico.

\section{Caracterización del COT de San Antonio de Areco}

SAA cuenta con un Plan de Ordenamiento Territorial en línea con lo dispuesto por el DL 8912/77. En el año 2004, la Municipalidad llamó a concurso para la elaboración de un "Plan de Ordenamiento Territorial", adjudicándose a la Universidad Nacional de La Plata (UNLP). En 2006, la universidad entregó el Informe Final "Plan de Ordenamiento 
Territorial del Partido de San Antonio de Areco" y su propuesta para el COT. Recién a fines de 2011, se aprobó por la Ordenanza 3647/11. Posteriormente, en 2012, se aprobó una modificación por medio de una nueva Ordenanza Municipal ( $\left.N^{\circ} 3754 / 12\right)$, siguiendo las observaciones que indicó la Dirección Provincial de Ordenamiento Urbano y Territorial. La Provincia lo aprobó en 2014 mediante el Decreto Provincial 12/2014.

El COT establece su revisión cada tres años, habiéndose actualizado en 2016 por medio de la Ordenanza $\mathrm{N}^{\circ}$ 4078. Como ejes principales fueron considerados: a) el fortalecimiento del perfil productivo de SAA; b) el acceso al suelo y la vivienda; c) el reconocimiento y dinamización del eje Av. Quetgles - Nuevo circuito bulevares; d) la gestión de la zona de preservación patrimonial y la búsqueda de una solución a las inundaciones.

El COT presenta aspectos destacables. Con relación a las inundaciones, SAA incorporó el "Mapa de Riesgo Hidrometeorológico y Vulnerabilidad Climática" al COT como herramienta preventiva para identificar las zonas de la ciudad que son afectadas por la inundación y mitigar o eliminar el riesgo hídrico, sumando sistemas de alerta y puntos de referencia. Por otro lado, en el plano de zonificación de la ciudad cabecera de SAA, se incorporó una restricción hidráulica que implica sólo podrán realizarse construcciones elevadas mediante pilotes a nivel fijo (de $+2,20$ m, tomados desde el punto medio de la Línea Municipal). El objetivo de la restricción es respetar el área de inundabilidad del río Areco y mantener la transparencia hidráulica de la zona.

La próxima extensión de la autovía de la RN N8 podría impulsar la irrupción de emprendimientos inmobiliarios privados en SAA, lo que implicaría la reconversión de tierras productivas para un uso residencial, fundamentalmente en las proximidades de la ruta que conecta a SAA con la RMBA. La ampliación de la RN N 8 disminuirá el tiempo de traslado desde la CABA y modificará el trazado de la ruta de ingreso a la ciudad cabecera, generando nuevos espacios entre la ruta y la zona urbana. Sin embargo, el COT no habilita la instalación de urbanizaciones cerradas. Estas son entendidas como "asentamientos privados que se construyen por fuera de la red pública de la ciudad, físicamente separada por un perímetro delimitado por algún tipo de cerramiento, con la producción privada de los servicios urbanos dentro de sus límites y con distintos servicios (seguridad, recolección de residuos, etc.) y actividades como recreación, educación, etc." (Ríos y Pirez 2008: 22). La normativa tampoco permite el crecimiento de la ciudad en los alrededores de la nueva autovía, existiendo además barreras naturales y artificiales como el río, las vías y las rutas que no permitirían el avance de la ciudad por fuera del ejido urbano ${ }^{15}$. Los funcionarios municipales prevén que la ciudad se extienda hacia el Este, donde todavía hay manzanas y lotes baldíos para urbanizar. Si bien el COT acompañaría ese crecimiento deseado, surge el interrogante acerca de la efectividad de la normativa para contener la valorización inmobiliaria de las tierras circundantes a la RN N8. Por otro lado, la elaboración de un Código de Ordenamiento Rural forma parte de la agenda pública municipal con el fin de sostener la tierra de uso agropecuario ${ }^{16}$.

\footnotetext{
${ }^{15}$ Entrevistas mantenidas con funcionarios municipales con motivo de la realización de un diagnóstico para la formulación del plan estratégico de turismo para el distrito (abril-mayo 2019).

${ }^{16}$ Entrevista realizada el 16 de abril 2019 al Secretario de Planificación, Luis Luppini, y al Director de Espacios Verdes, Francisco Rebollo Paz, ambos funcionarios de la Municipalidad de San Antonio de Areco.
} 


\section{La actividad turística de SAA}

SAA recibe anualmente una significativa demanda turística nacional e internacional. En 2016 se registró la llegada de alrededor de 300 mil turistas, entre los cuales casi un $7 \%$ fueron extranjeros ${ }^{17}$.

El patrimonio cultural de SAA constituye, junto al río Areco y el turismo rural, el principal atractor de la demanda. Pérez Winter (2013) expuso la dinámica del proceso de patrimonialización y turistificación de SAA, desde la década de 1930, mediante la creación del Parque Criollo y el Museo Gauchesco "Ricardo Güiraldes". En 1939, la Ley Provincial N. 4756 estableció el "Día de la Tradición", distinguiendo a SAA como sede de los actos celebratorios. A partir de entonces, fue reforzándose el vínculo entre SAA y el imaginario de la tradición gauchesca, particularmente a partir de su incorporación de la dinámica turística ${ }^{18}$.

En la década de 1970, la Municipalidad de SAA reconoció una serie de "lugares significativos". Posteriormente, el Decreto Nacional 1305/1999 declaró una serie de edificaciones urbanas y rurales como Monumentos Históricos Nacionales. Dicha norma también estableció como "Bien de Interés Histórico Nacional" a un sector del casco urbano de SAA y a la estación del Ferrocarril Nuevo Central Argentino ${ }^{19}$.

Lo gauchesco y lo tradicional se encuentran presentes de forma hegemónica en el discurso asociado al patrimonio cultural de SAA, reproduciéndose por medio de celebraciones como la Fiesta Nacional de la Tradición ${ }^{20}$. Fernández Balboa (2012) interpreta a SAA como un ecomuseo, asignándose a la idea "eco" un sentido asociado a una acepción de casa u hogar ${ }^{21}$. Esto sería una de las razones fundamentales para entender el posicionamiento de SAA en el mercado turístico.

También el río Areco, en su paso por la ciudad de SAA, constituye un sitio donde se concentra la demanda turística, siendo además utilizado como espacio recreativo por vecinos de la localidad. El río forma parte de la cuenca del río Areco cuya superficie es de 375.479 ha, y que abarca a nueve partidos bonaerenses (Solari et al., 1997). La red hidrográfica está conformada por el río Areco y varios arroyos y cañadas (Quevedo et al 1953).

Asimismo, parte de la demanda turística se concentra en espacios rurales (principalmente en estancias turísticas),

\footnotetext{
17 Según fuentes de la Dirección Municipal de Turismo de San Antonio de Areco, 2019.

${ }^{18}$ Respecto a los vínculos entre San Antonio de Areco y la idea de tradición, en 1939 por medio de la Ley 4.756 promulgada por la Legislatura de la provincia de Buenos Aires se determinó que el 10 de noviembre (fecha en que nació el escritor José Hernández) como "Día de la Tradición", colocando como sede de los actos oficiales al Parque Criollo y el Museo de Luján. En 1984 se la amplía y se declara solo a San Antonio de Areco como la "sede provincial permanente de la Tradición". Y en 1998 la Resolución 373/98 dictada por la Secretaría de Turismo de Nación también determinó como Sede Central de la Fiesta Nacional de la Tradición a la localidad de San Antonio de Areco.

${ }^{19}$ En los considerandos, se remarcó que San Antonio de Areco constituye uno de los poblados más antiguos de la provincia de Buenos Aires, además de contar con el río Areco, que fue marcado como mojón natural tras la fundación de Buenos Aires por Juan de Garay (1580). Véase: Decreto Nacional 1305/1999.

20 En el caso de San Antonio de Areco, desde hace décadas existen cuestionamientos sobre la "autenticidad" y el "relato" patrimonializador, que abarca tanto a los referentes simbólicos (en tanto representación alegórica de una identidad como también mercancía turística) y significados. Esto se evidencia en los debates vigentes entre diferentes sectores sociales, en particular sobre los estereotipos dominantes de "gaucho" (Pérez Winter, Cecilia. 2016: 231

${ }^{21}$ El sentido del ecomuseo sería entender un espacio donde las manifestaciones museales y patrimoniales expuestas en los espacios cerrados encuentran vida que se manifiesta en procesos cotidianos en el territorio circundante. Siguiendo esta idea, Fernández Balboa identificó a San Antonio de Areco como uno de pocos ecomuseos en Argentina, marcando que pocas comunidades presentan el sentido de pertenencia como la arequera, donde el espíritu gauchesco se observaría vivo en la cotidianeidad.
} 
incluyendo a las localidades de Villa Lía, Duggan y Vagues ${ }^{22}$.

\section{Análisis del COT de San Antonio de Areco en función de la actividad turística}

La zonificación del COT estableció una "Zona de Servicios Turísticos", la cual es definida asociada a los "sectores especializados donde se propicia la localización de actividades vinculadas al turismo y aquellas complementarias, así como a la recreación y el esparcimiento". De esta manera, se observa que el uso turístico del suelo es un criterio considerado en la zonificación del Municipio de SAA. Sin embargo, su utilización es muy restringida pues únicamente aplica a un conjunto de manzanas ubicadas sobre el Bv. Zerboni que bordea la costanera del río Areco, lo cual indica que la planificación pública considera únicamente a una demanda interesada por la costanera, como si el río Areco fuera el principal recurso turístico que impulsa la localización de las inversiones turísticas en estas áreas urbanas. Esto resulta incongruente con lo manifestado por los funcionarios municipales entrevistados, quienes priorizan el aprovechamiento del casco histórico como recurso histórico orientado a segmentos de la demanda nacional e internacional ${ }^{23}$. Asimismo, en la zona del casco histórico los residentes impulsan también la inversión turística, y en la planificación esta zona no es contemplada desde un enfoque turístico. El uso restringido de la "Zona de Servicios Turísticos", tiene una serie de consecuencias en relación con la planificación turística, que son justamente analizadas en este apartado.

En otra de las zonificaciones, se encuentra la "Zona de Esparcimiento", ubicada en las cercanías de la costanera que bordea al río Areco y al Parque Criollo. La misma se define como "la destinada principalmente a las actividades recreativas, el ocio activo y pasivo, con el equipamiento adecuado a dichos usos. Incluye los parques y áreas verdes afectadas con este destino en cualquiera de los núcleos urbanos del partido. Los clubes se consideran Zonas de esparcimiento semi-público". La figura utilizada resulta apropiada, pero su aplicación en el territorio también se observa con limitaciones.

Por otro lado, en los Distritos de Equipamiento se encuentra la "Zona Banda de Circulación" que se define como "la destinada a la localización de actividades vinculadas a las prestaciones de servicio al transporte automotor, de carga y de pasajeros, actividades agropecuarias y de servicios vinculadas al turismo en general". Dicha zonificación resulta destacable para la planificación turística, al incorporar al COT las áreas por donde circulan las personas y las mercaderías. Asimismo, dentro de las Áreas Especiales, se encuentra la "Zona de Preservación Patrimonial". La misma consiste en "aquellos sectores que incluyen a los inmuebles y sitios considerados de valor arquitectónico, estilístico, histórico, urbanístico o simbólico que forman parte de la memoria colectiva y de la identidad, cuya permanencia está sometida a acciones de preservación y/o protección".

\footnotetext{
22 Las localidades no tienen límites definidos, y cada una de ellas cuenta con una planta urbana cuya zonificación consiste en un área residencial, área complementaria, residencial extraurbana y el resto del territorio, corresponde al área rural.

${ }^{23}$ Entrevistas con funcionarios municipales en el marco de la elaboración de un diagnóstico para el plan estratégico de turismo (abril-mayo 2019 )
} 


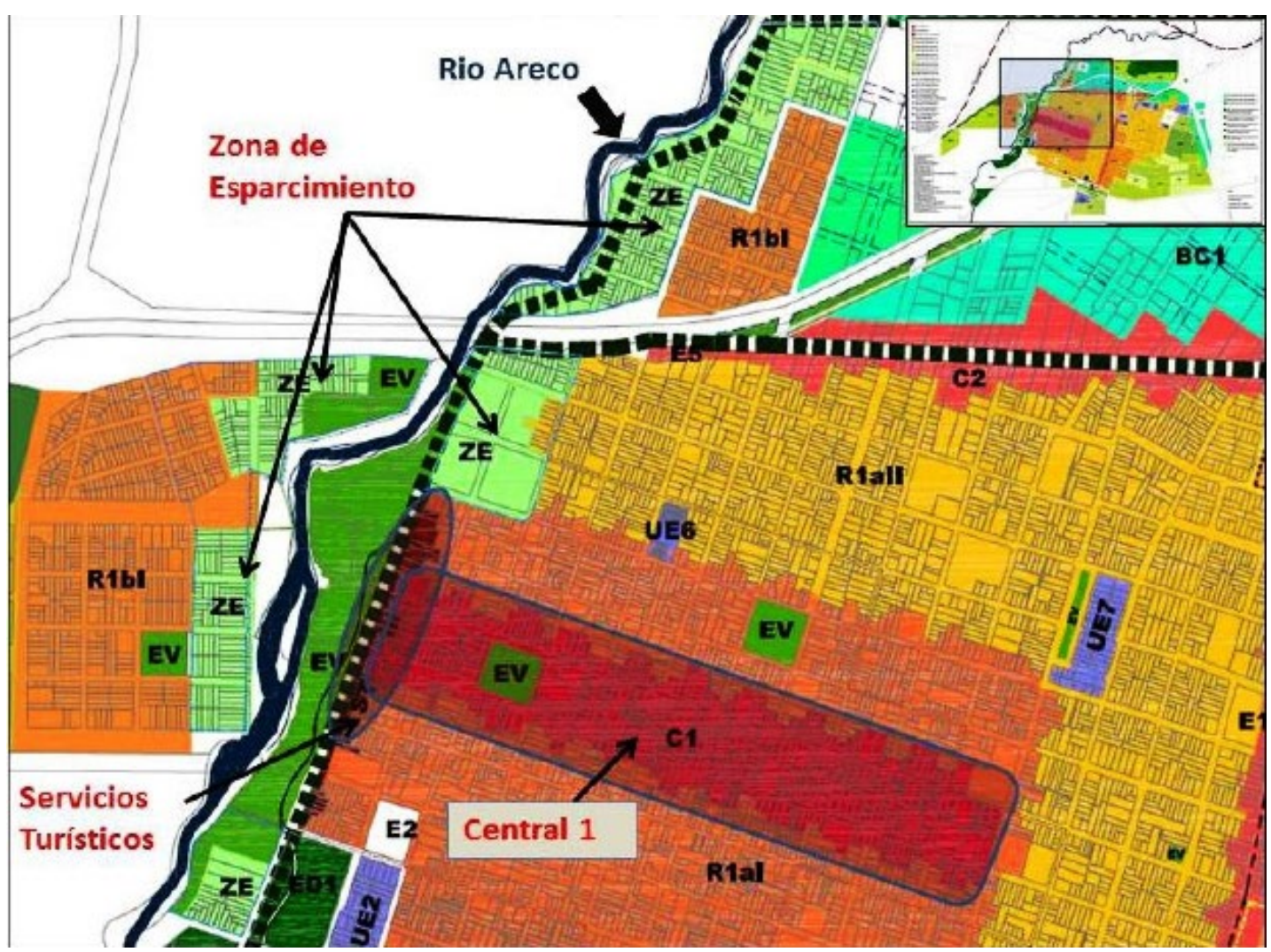

Fuente: Elaboración propia en base a la Ordenanza Municipal 4163/16

\section{Conclusiones}

En primer lugar, en el COT se observa que no se considera el uso turístico del suelo en el casco histórico (área zonificada como Central 1), siendo el sitio en el que se concentran numerosos establecimientos dedicados a la prestación de servicios turísticos (alojamientos, restaurantes, museos, locales de artesanías), y donde, además, el uso intensivo por parte de no residentes genera una serie de impactos en la infraestructura y el espacio público. Debe destacarse que la zona de patrimonio histórico se define en función de los valores asignados a una serie de referencias simbólicas legitimadas que representan la identidad de diferentes sujetos colectivos a nivel local. Es decir, no se asume al patrimonio ni al área de protección histórica como pasible de aprovechamiento turístico. Incluso, cuando los procesos institucionales de promoción turística la exponen como un producto de turismo cultural.

Por otro lado, el COT no contempla un uso diferenciado del suelo según se trate de residentes o de turistas, dado que está pensado en función de los primeros. Pero, de esta manera, se invisibiliza el uso intensivo que adquiere parte del territorio por la actividad turística, considerándose los usos parciales y normados (partiendo de un enfoque estático) en detrimento de los usos sociales reales (entendiendo el OT desde un enfoque más dinámico). 
Además, si bien se incorporaron en el COT las áreas de localización de clubes (entendidas como entidades semipúblicas por ser asociaciones civiles que prestan servicios contra el pago de la cuota societaria), los campos o emprendimientos rurales privados de uso turístico rural quedaron excluidos.

En otro orden, si se entiende a la planificación urbana desde un modelo centrado en la persona, el COT presenta algunas restricciones. En dicho modelo, la conectividad resulta un eje clave ligado no sólo a la movilización de personas y mercancías, sino fundamentalmente a la integración de espacios a través de recorridos histórico-culturales, turísticos o con una función económica específica (Alva 2019). Por ejemplo, en el COT no se visualizan las áreas de inversión turística municipal y/o provincial para la conformación de productos turísticos, como es el caso del Camino Real (recurso turístico potencial ubicado dentro del área periurbana de la ciudad cabecera), para el cual se colocó señalética específica a los efectos de impulsar la demanda turística al sitio. Estas zonas de inversión no se integran a una lógica o sistema turístico, y quedan aisladas de las áreas apropiadas por la demanda turística y en las cuales realizan un uso intensivo del suelo. Tampoco se han considerado en la planificación modalidades de uso turístico por fuera de las tipologías turísticas dominantes. Es así como, por ejemplo, tomando en cuenta la presencia de la Universidad Nacional de San Antonio de Areco (UNSADA) en cercanías a la Estación de Ferrocarril de SAA no se incorpora la idea de un polo de turismo MICE de carácter académico, técnico-científico ${ }^{24}$.

EI COT presenta una marcada orientación a ordenar la planta urbana construida u orientar la morfología y escala de las intervenciones futuras en SAA. Pero, a los efectos de la planificación turística, carece de un enfoque relacional y dinámico que dé cuenta de los usos reales del suelo por parte de residentes y turistas. Es decir, que permita visualizar las áreas donde la demanda furística provoca un uso intensivo del espacio construido, así como orientar los nuevos desarrollos en función de dicha actividad.

Al intervenir sobre un territorio que se constituye como resultado de múltiples procesos sociales y teniendo en cuenta que la demanda turística incrementa temporalmente la población real de un distrito, el COT no contempla los modos en que los sujetos se mueven espacialmente en función de sus prácticas de consumo y de recreación. En otras palabras, la forma de apropiación por parte de turistas y residentes. De hecho, parte del entramado comercial de la "Zona de protección patrimonial" se encuentra asociado a la prestación de servicios al turista. Un problema radica en la definición de los tipos de negocios comerciales que son adjetivables como "turísticos". Para resolver el problema, resulta fundamental incorporar la incidencia de la demanda turística en el consumo de los bienes y servicios ofrecidos por los distintos sectores económicos, utilizando métodos como el de la matriz de coeficientes fijos calculada por Sturzenegger y Porto (2009) $)^{25}$. Considerar esto en la actualización del COT implicaría entender mejor las relaciones entre la demanda turística y los usos del suelo de una forma dinámica que evite caracterizar como "servicios turísticos" únicamente a alguna actividad en particular, lo cual implica caer en un reduccionismo que dificulta los procesos de

\footnotetext{
${ }^{24}$ MICE es el acrónimo en inglés para el llamado en Argentina turismo de eventos o turismo de negocios. MICE refiere a meetings, incentives, conventions, exhibitions.

${ }^{25}$ En esta, se determinan los coeficientes de participación del turismo sobre el valor agregado bruto de cada una de las actividades económicas, lo cual implica, por ejemplo, que al sector hotelero (donde el sector turismo tiene una importancia significativa) se le aplique un coeficiente de $100 \%$ y, por el contrario, los restaurantes, bares y confiterías (que prestan servicio tanto a turistas como a residentes) se le asigne un coeficiente sustancialmente menor $(11,46 \%)$.
} 
planificación territorial.

Por otro lado, en las localidades rurales de Duggan y Villa Lía no se contempla el uso turístico del suelo. Como no se contempla ni el uso actual ni la proyección turística del uso del suelo en las localidades, no se pueden visualizar las zonas de usos turísticos actuales y futuras, y, entre otras complicaciones que esto genera, se observa que no se pueden tomar en cuenta las bandas de circulación de ingreso y egresos de los flujos turísticos y esto repercute en la falta de planificación de la señalética para la orientación de la demanda. Tampoco en Vagues (ubicada en un área periurbana y de baja densidad cercana a la Ciudad de SAA), se incluye el uso turístico del suelo, aun cuando allí hubo inversión turística del Estado como el Centro de Interpretación en la Estación Ferroviaria de Vagues. Esto significa que la inversión realizada no se consideró en forma integral, sino en forma aislada sin tomar en cuenta la demanda existente y la inversión turística privada. Cabe destacar que en las mencionadas localidades rurales de Duggan y Villa Lía, se registran actividades de turismo rural pero no así de agroturismo. Según Zambrano et al (2016 2) la OMT define al Turismo Rural como: "conjunto de actividades que se desarrollan en un entorno rural, excediendo el mero alojamiento y que pueden constituirse, para los habitantes del medio, en una fuente de ingresos complementarios a los tradicionalmente dependientes del sector primario, convirtiéndose en un rubro productivo más de la empresa agropecuaria". De acuerdo a esta definición, el turismo rural tiene como característica central el ámbito rural en el que se desarrolla y dentro de todas las actividades que abarca el turismo rural, el agroturismo sería una de ellas, en particular, que permite al turista involucrarse en la forma de vida del productor y su familia, observar y/o participar de prácticas productivas y en el procesamiento de productos agropecuarios con la organización de visitas a actividades productivas de bienes primarios, artesanales y agroindustriales. Es decir, en principio el agroturismo es una forma de turismo rural en el que las actividades no sólo son realizadas en el medio rural y resultan un complemento de la actividad productiva del productor, sino que fundamentalmente están relacionadas a la explotación agropecuaria, brindando la opción de participar en las labores del campo. Justamente lo que no se observa en SAA son actividades de agroturismo en las que además tengan participación los pequeños y medianos productores familiares en la oferta de servicios turísticos.

Finalmente, al no existir un Plan Integrado de Manejo Ribereño en SAA, no se pueden determinar los distintos usos turísticos y recreativos que puede tener el rio Areco en su curso en todo el distrito, lo cual dificulta la planificación del desarrollo turístico. Por ejemplo, la determinación de posibles senderos ribereños, caminos rurales de uso público, zonas de recreación en lugares cercanos como Duggan, la instalación de unidades fiscales para usos turísticos, las formas de acceso desde las áreas urbanas, y también desde las periurbanas y rurales. Sería interesante, incluso, articular una planificación supralocal, integrando a los municipios linderos para favorecer el diseño de productos turísticos de bajo impacto ambiental.

En síntesis, resulta auspicioso que la Municipalidad de SAA haya iniciado la planificación de los usos del suelo de su territorio, así como que, en la actualización del COT, el turismo (actividad que contribuye significativamente al PBG municipal) haya sido considerado. Pero caben mencionarse una serie de restricciones y simplificaciones. En primer lugar, la zonificación de las áreas de servicios turísticos fue ubicada en un área muy restringida, siendo además excluido el centro histórico de esta zonificación. Por otro lado, los procesos turísticos realizados en el territorio municipal de SAA exceden a las áreas urbanas, abarcando también a las áreas periurbanas y rurales. Es así como el turismo rural 
no es considerado en el OT de SAA, lo cual dificulta la determinación de los usos del suelo rural ligados a los flujos de la demanda turística, en el marco de una planificación integral del municipio. El DL 8.912/77 no contempla a los espacios rurales como zonas con un uso del suelo ligado al esparcimiento, marcándose así una diferencia respecto a los usos urbanos. Esta puede ser una de las causas de que el COT de SAA no incorpore los usos turísticos en áreas rurales, más allá que en estas se localicen grandes emprendimientos turísticos promocionados institucionalmente por la Municipalidad.

Esta situación señalada se puede explicar por una sumatoria de factores, algunos de ellos están relacionados con la formación de los equipos técnicos que se encargan de la elaboración de los planes y códigos de ordenamiento, en los que los funcionarios de la cartera turística, así como profesionales del turismo y de otras disciplinas como la sociología o la antropología no son incluidos. A esto se suma que uno de los ejes del OT, como es la participación ciudadana, no se haya implementado en el caso de la elaboración del COT de San Antonio de Areco. Es decir, en su actualización no hubo espacios de participación de los distintos actores de la sociedad, entre ellos, los relacionados con el turismo como: prestadores, inversores, guías de turismo y otros de interés del sector, entre otros.

El análisis realizado y las conclusiones del caso de SAA son pertinentes para otros municipios de la provincia de Buenos Aires en los que el turismo constituye una actividad de importancia. De esta manera, resulta apropiado considerar el uso turístico del suelo de acuerdo a un modelo de desarrollo urbano deseado así como la incidencia del turismo en el PBG municipal y, particularmente, la integración de las diferentes áreas que son utilizadas por la demanda turística. Para ello es necesario profundizar en los procesos de planeamiento y diseñar instrumentos técnicos que integren la dinámica turística en la planificación territorial. Asimismo, para facilitar la evaluación de los efectos de la actividad como resultado del uso intensivo del territorio, del aumento de los flujos de circulación y de su integración con el resto de los usos en la jurisdicción municipal.

Por último, se podría integrar los COT a sistemas de inteligencia urbana que permitan generar indicadores "en tiempo real" (Alva 2019) para una planificación dinámica de estrategias territoriales y políticas turísticas.

\section{Referencias Bibliográficas}

-Alva, Benjamín. (2019). "Los retos de la agenda urbana desde lo local y la estrategia multiescalar en América Latina". En: L. M. Cuervo y M. del P. Délano (eds.). "Planificación multiescalar: las desigualdades territoriales. Volumen II". Serie Seminarios y Conferencias, № 92 (LC/TS.2019/54), Santiago, Comisión Económica para América Latina y el Caribe (CEPAL).

-Alves Rolo R. (2014). "Desafíos para la construcción de una política de ordenamiento territorial en la Argentina". Tesis presentada para optar al título de Magister de la Universidad de Buenos Aires, Área Desarrollo Rural. Escuela para Graduados Alberto Soriano. Facultad de Agronomía, Universidad de Buenos Aires. 
Carrasco, Maribel. (2018). "El marco normativo del ordenamiento territorial y las políticas públicas municipales en relación al avance de las urbanizaciones cerradas sobre tierras de uso agropecuario, valles de inundación y humedales del Partido de Escobar, Provincia de Buenos Aires". Tesis presentada para optar al título de Magister de la Universidad de Buenos Aires, Área Desarrollo Rural. Escuela para Graduados Alberto Soriano. Facultad de Agronomía, Universidad de Buenos Aires.

-Chaves Viviana y Weiler Cornelio (2016). "Los estudios de casos como enfoque metodológico". ACADEMO Revista de Investigación en Ciencias Sociales y Humanidades - Universidad Americana. Diciembre, 2016, Vol. 3 Nro. 2.

-Creswell, J. (1998). "Qualitative inquiry and research design. Choosing among five traditions". USA: Sage.

-Decreto Nacional 1.305/1999.

-Decreto Ley 8.912 de la provincia de Buenos Aires.

-Decreto Ley 6.769/58 de la provincia de Buenos Aires.

-Elverdín, Julio; Ledesma, Sandra E.; Zain El Din, Erika; Cittadini, Eduardo (ed.). (2014). “Programa Nacional para el Desarrollo y la Sustentabilidad de los Territorios". Colección Investigación, Desarrollo e Innovación. INTA Ediciones.

-García Delgado, Daniel (1998). "Estado-nación y globalización". Editora Espasa Calpe Argentina S.A./ Ariel, Ciudad Autónoma de Buenos Aires.

-Fernández Balboa, Carlos. (2012). "El gaucho. Manifiesto del hombre criollo". En: Arias Incolla, María de las Nieves (comp.). "Patrimonio Argentino 15. Fiestas típicas, culto popular, gastronomía, música y otros". Primera Edición. Edición literaria a cargo de Berto González Montaner. Arte Gráfico Editorial Argentino, Buenos Aires. Pp. 104-113.

-Flores, Pamela; Isasi, María Teresa; Martín, Irene; Miño, Mariela; Ruggerio, Carlos A. (2013). “Diagnóstico ambiental de la ciudad de San Antonio de Areco". Universidad Nacional de General Sarmiento, Los Polvorines.

-García Delgado, Daniel (1998). "Estado-nación y globalización". Editora Espasa Calpe Argentina S.A. / Ariel, Ciudad Autónoma de Buenos Aires.

-Grandinetti, Rita; Nari, Patricia. (2016). "Gobernanza territorial: la difícil y tensiva articulación de la acción pública urbana". En: Rofman, Adriana (comp.). "Participación, políticas públicas y territorio. Aportes para la construcción de una perspectiva integral". Ediciones UNGS, Universidad Nacional de General Sarmiento, Los Polvorines. Pp. 53-71. 
-Hernández-Sampieri, R. \& Mendoza, C (2018). "Metodología de la investigación. Las rutas cuantitativa, cualitativa y mixta". Ciudad de México, México: Editorial Mc Graw Hill Education, Año de edición: 2018, ISBN: 978-1-45626096-5, $714 \mathrm{p}$.

-Instituto Nacional de Tecnología Agropecuaria (INTA). Proyecto Regional con Enfoque Territorial (2013). "Contribución al desarrollo sustentable del territorio ganadero del Salado" (Mimeo).

-Ley Integral del Medio Ambiente y los Recursos Naturales de la provincia de Buenos Aires No 11.723.

-Ley Nacional de Turismo $N^{\circ} 25.997$.

-Manzanal, Mabel. (2007). "El desarrollo rural en Argentina: una perspectiva crítica". En: Workshop Internacional: "Políticas Públicas e Desenvolvimento Rural No Cone Sul". Porto Alegre, 20 a 23 de novembro. Programa de Pós-Graduação em Desenvolvimento Rural (PGDR), da Universidade Federal do Rio Grande do Sul (UFRGS).

-Municipalidad de San Antonio de Areco en convenio con la Universidad Nacional de La Plata - FAU- Plan de Ordenamiento Territorial del Partido de San Antonio de Areco, Provincia De Buenos Aires, septiembre 2006.

-Naciones Unidas. (2018). "La agenda 2030 y los objetivos de desarrollo sostenible: una oportunidad para América Latina y el Caribe". LC/G.2681-P/Rev.3, Santiago.

-Norma UNE 178501:2016. "Sistema de gestión de los destinos turísticos inteligentes".

-Ordenanza Municipal 4163/16 de San Antonio de Areco.

-Organización Mundial de Turismo. (2017). “Declaración de Chengdu sobre «El turismo y los Objetivos de Desarrollo Sostenible»".

-Pérez Winter, Cecilia. (2013). "Gaucholandia", cuando el patrimonio entra en disputa en San Antonio de Areco". VII Jornadas Santiago Wallace de Investigación en Antropología Social. Sección de Antropología Social. Instituto de Ciencias Antropológicas. Facultad de Filosofía y Letras, UBA, Buenos Aires, 2013.

-Pérez Winter, Cecilia. (2016). "¿̇"Tierra de Gauchos" o "Gaucholandia"? Autenticidad en San Antonio de Areco (Argentina)". Revista Pasos, Vol. 14 Núm. 5.

-Quevedo, V., Prego, A., Tallarico, L, Bellon C. y Calcagno, J. (1953). "Aptitud de las tierras del partido de San Antonio de Areco". Revista de Investigaciones Agrícolas. No 28. Instituto de Suelos y Agrotecnia. Ministerios de Agricultura 
y Ganadería. Dirección General de Investigaciones Agrícolas.

-Reese, E. (1999). "Planes estratégicos: limitaciones y oportunidades". Curso internacional, Ciudad futura nuevas modalidades en planificación y gestión de ciudades. Rosario.

-Ríos, Diego y Pírez, Pedro. (2008). “Urbanizaciones cerradas en áreas inundables del municipio de Tigre: ¿producción de espacio urbano de alta calidad ambientale?". EURE (Santiago). Abril, 2008, Vol. 34, N 101. pp. 99-1 19.

-Ríos Licia (2017). "Las capacidades estatales y políticas de Ordenamiento Territorial. Municipios de la Provincia de Buenos Aires en el contexto pos-neoliberal (2003 -2015)". Tesis presentada para optar al título de Doctora en Arquitectura y Urbanismo de la Facultad de Arquitectura y Urbanismo de la Universidad Nacional de La Plata.

-Rossi, E.; Charne, U. y Comparato, G. (2018). "Turismo y ambiente: repensar la actividad turística desde la sustentabilidad". Editorial de la Universidad de La Plata, Universidad Nacional de La Plata.

-Solari, F, Larran, My Lorenzo, E. (1997). "Caracterización de la cuenca del río Areco para su gestión ambiental según parámetros cartográficos". Agro-Ciencia. Chile.

-Stake, R. E. (2005). "Investigación con estudio de casos". Madrid, Morata.

-Sturzenegger, Adolfo; Porto, Natalia. (2009). "Informe económico anual sobre la actividad de viajes y turismo". Cámara Argentina de Turismo. Argentina.

-Subsecretaría de Planificación Territorial de la Inversión Pública de la Nación. (2015). "Lineamientos para la planificación territorial. República Argentina". [En línea]. Avance III, Plan Estratégico Territorial, Ministerio de Planificación Federal, Inversión Pública y Servicios. Disponible en: https://www.mininterior.gov.ar/planificacion/pdf/Lineamientos-planificacion-territorial-(2015).pdf [Consulta: 10 de enero 2020].

-Subsecretaría de Planificación Territorial de la Inversión Pública de la Nación. (2016). "Guía de planificación territorial". [En línea]. Ministerio de Planificación Federal, Inversión Pública y Servicios. Disponible en: https://www. mininterior.gob.ar/planificacion/pdf/AS_14659169801.pdf [Consulta: 5 de enero de 2020].

-Yin, R. (1994): Case Study Research: Design and Methods. Sage Publications, Thousand Oaks, CA.

-Zambrano Fernando, González Delymar y Peñaloza Rossy (2016), "El turismo rural una visión desde el ámbito internacional, nacional y del estado Táchira - Venezuela", Aibi revista de investigación, administración e ingeniería. Volumen 5, Número 1 de 2017, Pág. 36-44. 